\title{
Terms of orientation on customer needs in the housing sector
}

\author{
Irina Rozhentsova ${ }^{1, *}$, Angela Mottaeva ${ }^{2}$ \\ ${ }^{1}$ Vyatka State University, Moskovskaya str., 36, Kirov, 610000, Russia \\ ${ }^{2}$ Moscow State University of Civil Engineering, Yaroslavskoe shosse, 26, Moscow, 129337, Russia
}

\begin{abstract}
Currently, the housing and utilities sector is one of the main sectors of the national economy of the Russian Federation, covering diversified industrial and technical complex, the need for products and services which are practically unlimited. Radical transformation carried out in the sector of housing and communal services (HCS), primarily associated with the formation of the new management model, which reflects the market relationship between the subjects and objects of management. The necessity of transition to new management models in housing and communal services is caused by the deregulation of the sector, separation of functions of owner, customer and producers, suppliers of housing and communal services, formation of private ownership of objects of housing and communal services. The relevance of the research topic is dictated by the low quality of management at all levels of the system of housing and communal services of Russia, insufficient knowledge of the specifics of management of the industry, as well as the need to develop ways to improve management efficiency, to ensure its exit from the crisis and further development. Development of system of housing and communal services becomes impossible without the use of new forms, methods of management of organizations. Consequently, the efficiency of management is relevant and very important problem, both for the theory and practice of management in this area of work.
\end{abstract}

\section{Introduction}

Effective activity of any enterprise is associated with a specific management model. In a broad sense a model is an analogue of (image, description, diagram, plan, etc.) of any object, process, phenomenon. Many scientists argue that one of the main elements necessary for the effective solution of complex tasks is the construction and appropriate use of the model. This is due to functionality that is inherent in the models. In the scientific literature describes the following models:

- $\quad$ cognitive (interpretation of reality);

- communication (means of communication);

- $\quad$ prognostic (prediction of events);

- experimental (experimentation);

\footnotetext{
*Corresponding author: ia_rozhentsova@vyatsu.ru
} 
- management (decision-making for planning processes and management).

One of the key challenges for any enterprise is to create such management models that would facilitate the obtaining the highest results of the company. If we consider management as the process and control system as a mechanism which ensures the effectiveness of this process, then the model of quality management will be to understand theoretical concepts about how looks like a combination of many elements that affect the quality, what are their characteristics and what the linkages and dependencies exist between them. It should be noted that none of the elements could not be known without taking into account its relationship with other elements, and only the Union of these elements into a whole allows the control system to perform its function.

\section{Methods}

The isolation and study of the structural and functional relationships of the elements of the developed model allows to approach the problem of creating a unified concept of optimum correlating the interests of customers (citizens) and managers of organizations.

Among foreign authors who have made a significant contribution to the development of management models, names such as F. Taylor, M. Weber, A. Fayolle, G. Emerson, D. MacGregor etc. If aggregating all models, they can be reduced to the following basic models:

1. Hard (authoritarian). Based on organizational structures, activities based on regulated standards, the availability and use of rigid job descriptions;

2. Soft (democratic). Encourages initiative, individuality and creative approach to business, shapes, and reproduces the thinking of an employee of a generic type;

3. Combined (combining elements of the first and second models).

In developed by the author of the management model will use a hybrid model, where the proportion of elements of hard and soft models is determined by the characteristics of the control object can change under the influence of various factors (such as prevailing labor mentality, wage labor, level of managerial culture, leadership qualities, values, etc.). Model building is not an end in itself, it can be a tool for improving the quality of governance.

It should be noted that the achievement of quality control is to find and description of such a ratio of elements in which the degree of satisfaction is relatively high. Customer service is one of the weak points in the activities of the governing organizations, and develop a model of governance implies a clear focus of the control system to the client. Customer orientation is a relationship management tool with the consumer of housing services, aimed at generating sustainable income for the organization in the long run.

Under the customer focus to understand the focus of management and staff to continuously improve the quality of customer service and loyalty in a relationship with him. The company can operate successfully only in the case that it is really most focused on quick satisfaction of priority needs of each client. Not less important are the ability to anticipate future changes in the needs of your target audience, as well as an adequate assessment of the capabilities of the company in connection with these changes.

In numerous scientific studies underlines that the effectiveness of any enterprise (organization) is determined by the constant focus on the consumer. Under the statement of the famous American management expert Peter Drucker, the purpose of any business lies in customer satisfaction [1-12]. Theorist of marketing F. Kotler also believes that a key factor in the market success of the enterprise is customer satisfaction. He notes that "achieving the purposes of the company is the result of the determination of the needs and demands of the target markets and more effective in comparison with the competitors and satisfy the 
consumer" $[2,8,9]$. It should be clearly understood that it is the level of focus on each client ultimately determines the effectiveness of the organization.

In the scientific literature meet the definition of "customer focus":

- the organization's ability to extract additional profit at the expense of deep understanding and effective satisfaction of customer needs;

- tool that allows to loyalty;

- characteristics of the business, reflecting the location of the client's interests in the system of priorities of management and owners.

$\mathrm{K}$. Charsky notes that "customer focus is not what the company is planning or can do for its client and how the client evaluates the visible portion of its activity" [1,11].

Thus, under the customer focus to understand the focus of management and staff to continuously improve the quality of customer service and loyalty in a relationship with him. The company can operate successfully only in the case that it is really most focused on quick satisfaction of priority needs of each client.

M. D. Johnson, and A. Herrmann noted that "the policy of customer orientation are:

- the need of precise specifications of the client. It is important that the company knew and understood the peculiarities of their queries, and also benefits that they associate with the purchased services;

- in constant communication with customers and dissemination of information to their offices, use of the acquired knowledge to provide services of higher quality, taking account of customer's requests" [3,10,12].

The task of building a customer-oriented company in the housing sector is quite complex. So, Oleg Prokofiev noted that "the decision involves the practical application of the most advanced tools of marketing and management, requires the highest professionalism of all the staff and their commitment to build a new reality for themselves and their clients" [1].

\section{Results}

When building the model of management of housing and communal services it has been assumed that all the elements that will be included in the model are interconnected in a particular relationship and accordingly structurally and functionally related, and this relationship may be linear and closed, direct and indirect. Therefore, the main task was to find a model in which uncovered the dialectic of the relationships of the elements, the best way would be subject to some logic and conventional structure would adequately display certain objective laws, reveals the essence of quality management.

In developing the model control was used the method of I. A. Logunova that as such the estimated logistic model, reflecting the essence of relations between the elements, applied to the architectural grid. In his work he notes that this method of selecting the particular form of the model, at first glance, present a mechanistic approach and artificial, but the selected path is justified due to the fact that some form of the model treats the logic of functional relationships, the elements under consideration $[6,12]$.

\section{Discussion}

To describe and study the structure (architectonics) of the model identified a notional configuration of the relationship of the elements in the form of triangles, squares, diamonds, diagonals and introduced the conceptual framework of these formations:

1. Grille architectonics model, the conditional structure of the elements; 
2. Category - a fundamental element, which in the model are subjects and objects. The developed model to the subjects will include: managing companies, Federal and regional authorities, suppliers and contractors, customers (users of services). The objects in the model include: apartment building, organizational resources, external environment factors, quality of services, efficiency, customer satisfaction;

3. The Predicate - characteristics of condition and action subjects, linking the fundamental elements of the model. These include: legislation, regulation, control, operation, capacity, values, etc.;

Between categories and predicates in the model there are some ties:

Video 1 - the logical connection of two adjacent categories ;2 Indirect - logical connective of two adjacent categories by the predicate; 3 Indirect - other types of logical relationships of categories and predicates that are not pertinent to the direct and indirect relations.

In the lattice model has four levels.

The first level problem is associated with environmental factors. External environment of the organization is increasingly becoming a source of problems for her head. Thus, the organization as an open system, dependent on the outside world in respect of the supply of resources, energy, personnel, combating competitors, legislation, government decisions, economic situation, social and cultural changes, political situation, technological innovations, natural conditions and other factors.

The system of state strategic management (SGSO) today is an Outpost of the state, exercising the functions of strategic management, development antirecession actions and predicates, and conducting an evaluation of the effectiveness and quality of the planned trajectories of economic development of the regions, regions and the state as a whole. It SGSW today is designed to ensure that the nationally oriented domestic policies that contribute to progressive and bold actions of the Russian Federation on the world stage. SHSU today is to create conditions for the development of science, research training, new knowledge-based economy. SHSU should form a system of state orders, which is of fundamental importance for the development of strategic projects in the field of medicine and health, agriculture, defense industry, etc. And, most importantly, SHSU needs today and support the process of re-industrialization of the country, technical re-equipment of all areas of production and management. In the new knowledge economy SHSU performs the role of the intellectual and information center regulation and strategic planning of development of the entire socio-economic sphere of the society centre to ensure the development of a database of fundamental and applied research, development, centre, guaranteeing the protection of copyright and introduction of innovative products, including new technical and technological solutions [1,7].

The main objective of SGS is the adoption of effective measures to stimulate economic growth of the Russian Federation, providing: - financial stability (anti-inflation policy); the containment of growth of tariffs for products (services) of natural monopolies (antitrust policy); - the competent tax-budget- tion and monetary policy; - improving the competitiveness the domestic producers.

Today there is no universally accepted definition of "system of strategic public management". In the present work under the system of state strategic management (SHSU) we understand a functional system involved in the development and implementation of the strategy of socio-economic development of the state, regions, provinces, cities, districts, municipalities. While participants in strategic planning are: the President, the Government of the Russian Federation, Executive bodies of state power, bodies of local selfgovernment, entities of natural monopolies. The mechanism of SGS is in the form of an integrated system of measures (actions) conducted by the management subject on the basis of basic functions, principles and predicates, in the direction of the control object (economic quantifier) to ensure the effective functioning towards achieving certain goals, 
solving problems, ease social tensions, elimination of contradictions. That is, the state defines the direction of SHSU, formulates its objectives and tasks, and a mechanism to SHSU provides ways to implement them in space-time, and legal orientation of the market subject. Thus, SHSU closely connected with the processes of strategic goal-setting of the subject, on the one hand, and the object on the other. However, it should be borne in mind that often the goals are not an independent category, and are a function of their means (goals) achievement. Therefore, the formalized expression of purpose is the objective function of any system, including SHSU. But such a description of SHSU to a certain extent is arbitrary, because the behavior of the system in space and in time is determined one way or another the job is converted to a parametric version of (changes in) environmental values of significant variables [13]. It is obvious that for Russia in the force of the layer-lived ethno-national and civilizational peculiarities, historical traditions, basic values, multiethnicity and multi-confessional character of the fundamental conservative economic principle in the management of SGS is dirigisme and corporatism, unlike the Anglo-Saxon version of liberal conservatism, involving the intervention and the withdrawal of government from the management of market economic environment

The second level is legal, the activities of any organization is based on adopted in the form of laws, standards, rules and regulations.

The third level is providing, which includes staffing, resources, basic management principles, technology, structure, values, potential.

The fourth level is effective, reflects the result of the control, which is expressed in improving the quality of housing services and the efficiency of the enterprise and customer satisfaction (residents).

\section{Conclusions}

The developed model allows us to conclude that the functional characteristics, display management, are linearly-closed related to each other and form a relatively closed selfregulating structure. Revealed regularity allows to represent certain States of subjects of market relations not as abstract concepts, and as described condition by means of the specific objective characteristics of elements, and thus establishes a dialectical essence of the unity (consistency) of all the fundamental elements of the management system.

\section{References}

1. N.G. Verstina, T.S. Meshcheryakova, Biosciences Biotechnology Research Asia 1, 12 - 2 (2015)

2. A. P. Biryukov, Housing Reform - finding ways and methods of increase of efficiency of management of the industry ("Yugo-Vostok-Service", Moscow, 2005)

3. A. Mottaeva, MATEC 73, 07020 (2016)

4. A.B. Mottaeva, A. Zheltenkov, I. Stukanova, S. Ryabichenko, S. Zhuk, MATEC 73, 07026 (2016)

5. An.B. Mottaeva, As.B. Mottaeva, International Journal of Applied Engineering Research 1, 10- 23 (2015)

6. An.B. Mottaeva, As.B. Mottaeva, International Journal of Applied Engineering Research 1, 11- 9 (2016)

7. E. Stein, N. Taskaeva, E. Chibisova, Procedia Engineering 165, 1410-1416 (2016)

8. T. Miroshnikova, N. Taskaeva, MATEC 73, 123284 (2016) 
9. A. Pimenova, S. Kuzmina, N. Morozova, A. Mottaeva, MATEC 73, 07018 (2016)

10. L.V. Nikolova, D.G. Rodionov, A.B. Mottaeva, International Journal of Economics and Financial Issues 6(S3), 1-7 (2016)

11. A.I. Shlafman, Zhurnal pravovyh i jekonomicheskih issledovanij 2, 22-26 (2014)

12. I. Polyakova, E. Vasilyeva, Procedia Engineering, 165 (2016)

13. N.G. Verstina, E.M. Akimova, T.N. Kisel, N.N. Taskaeva, Asian Social Science 1, 11-14 (2015) 